\title{
Maternal self-efficacy and maternal perception of child language competence in pre-school children with a communication disability
}

- M. Harty

- E. Alant and

- C. J. E. Uys

Centre for Augmentative and Alternative Communication, University of Pretoria, Main Campus, Pretoria, Gauteng, South Africa

Michal Harty, Centre for Augmentative and Alternative Communication, University of Pretoria, Main Campus, Cnr Lynwood and Roper Streets, Pretoria, Gauteng, South Africa 0002

\section{Abstract}

Background The aim of this study was to describe maternal self-efficacy beliefs within the parenting domain and maternal ratings of pre-school children's language abilities, where the child has a communication disability. The association between these two constructs was also investigated.

Method Twenty-five mothers completed a questionnaire consisting of two subsections: parental self-efficacy and maternal rating of child language ability. Convenience sampling was used, and mothers with children attending four specialeducation schools in the Pretoria area consented to participate in the study. Results The results revealed that mothers generally had high self-efficacy beliefs within certain parenting roles, in spite of the fact that their child has a communication disability. The lowest competence was reported in discipline and teaching roles. In addition, mothers' reports of patterns of child ability correlated with what has been written in the literature. Correlation statistics generally revealed weak association between the constructs, with the strongest association between the parental domain of discipline and maternal reports of their child's receptive language abilities. 
Conclusions Possible reasons for the weak correlation values are proposed. These include factors that may alter the way parents of children with disabilities construct and maintain self-efficacy beliefs; as well as the fact that the two sections of the questionnaire measure maternal appraisals at two very different levels (objective observations and evaluative self-regulatory processes).

\section{Introduction}

'Self-efficacy is a belief in one's own capabilities to organize and execute the courses of action required to manage prospective situations' (Bandura 1995, p 2). Haidt and Rodin (1999) state that self-efficacy beliefs are among the best predictors of success and performance in many contexts. It is clear from the literature that a reciprocal nature exists between self-efficacy beliefs and actions or behaviour (Shelton 1990). The very factors that influence the development of self-efficacy, such as the perception of experience and self-attributional process, are in themselves mediated by a person's self-efficacy beliefs. This implies that individuals with negative experiences within a specific domain, as well as a perception of their inability or inadequacy to perform certain tasks, are likely to have poorer self-efficacy beliefs. This will negatively impact on their performance in these activities and attainment of the goals they choose, as well as the implementation of coping strategies. Thus, optimal performance and behaviour may be compromised. Because self-efficacy is domain-specific and is likely to vary for different behaviours in different domains, it may be a particularly significant factor in understanding the effects that a childhood disability has on parents (Hastings \& Brown 2002).

In the parenting domain, self-efficacy has been shown to impact on parental behaviours and parenting stress. Various studies (Mash \& Johnston 1983; Johnston \& Mash 1989; Wells-Parker et al. 1990; Teti \& Gelfand 1991; Coleman \& Karraker 1998; Scheel \& Rieckmann 1998; Hastings \& Brown 2002) have investigated the role of self-efficacy in relation to predicting parenting practices, as well as the mediating role that it plays in relation to perceived child temperament, parent-child interaction and bonding, as well as perceived maternal stress and depression. Teti and Gelfand (1991) investigated the link between self-efficacy and various aspects of maternal behaviour including depression, perception of child difficulty and social-marital supports. The results they obtained indicate that self-efficacy and 
maternal reports of competence are positively related. They state that self-efficacy plays a mediational role between perception of child behaviour and maternal feelings of competence, as well as having a direct impact on mothers' behaviour towards their child. This implies that if maternal self-efficacy is controlled for, neither maternal competence nor external support is significantly related to maternal behaviour. Similarly, Mash and Johnston (1983) report an inverse relationship between parenting competence and parents' own perception of their child's behaviour problem. Results from their study indicate that parents of children with behaviour problems perceive themselves as significantly less skilled and knowledgeable in their roles as parents, and derive less value and comfort from their parenting roles than do parents of typical children. They also report a strong correlation between mothers' perception of child behaviour problems and parenting stress. They suggest that having a child with a disability such as behaviour problems creates ongoing stress for parents that may negatively influence their competence.

There have been some studies that found insignificant correlations between maternal self-efficacy and child and parental outcomes. Coleman (1998) investigated maternal efficacy as a predictor of parenting competence and toddler development. Contrary to her hypothesis, domain-specific and general efficacy scale ratings failed to predict parenting stress or child behaviour. However, the author found that domain-specific self-efficacy beliefs do operate as a mediator between perception of toddler temperament and parenting stress and satisfaction. Hastings and Brown (2002) identified self-efficacy as an important variable in understanding relationships between child behaviour problems in children with autism and parental mental health outcomes. However, their data reveal that efficacy has a different effect on outcomes depending on parental gender. Results for mothers indicated that self-efficacy functioned as a mediator of maternal perception of child behaviour problems and mothers' mental health outcome. For fathers, however, self-efficacy was a moderating variable, in that it reduced the impact of child behaviour problems on anxiety only for those fathers dealing with the most difficult children.

The studies just mentioned highlight the fact that parental self-efficacy could be affected by gender, perceived parental stress and child behaviour problems. Likewise, the studies suggest that parenting belief of self-efficacy also has a mediating role to play between perceptions of stress, and perceptions of child difficulty and behaviour 
problems, as well as having an influence on the type of coping strategies parents use to mitigate stress.

Schwarzer (1992) states that the number and quality of action plans an individual makes and executes are dependent on his or her perceived competence or self-efficacy beliefs. According to the health action process approach, once an action has been initiated, it has to be controlled by cognition in order to be maintained. While the behaviour is being performed, self-efficacy determines the amount of effort invested and degree of perseverance with the action or behaviour. Schwarzer states that people with a strong belief of self-efficacy visualize success scenarios that guide their actions and let them persevere under difficult situations. Schwarzer states that self-efficacy affects the initiation and persistence of coping behaviour in a stressful situation where there is no evident or immediate solution to the problem. Although no direct applications to parenting practices are implied in his discussion of this model, applicability to this context seems feasible. This is congruent with Bandura (1989) as he states that people who have higher beliefs of self-efficacy in a given domain will think, feel and act differently from those who perceive themselves as less efficacious. In addition, it is also possible that high self-efficacy beliefs may allow individuals to become more self-critical and may suppress the human tendency to attribute failure to external causes. In so doing, by becoming more open in acknowledging problems, these individuals may pave the way for proactive approaches to problem solving. In addition, Scheel and Rieckmann (1998) state that without strong parental self-efficacy beliefs, generalization and success of intervention appears to be in jeopardy as these parents who often feel disempowered (attribute outcomes to factors outside their control) are less likely to participate fully in the intervention process. Therefore, strong positive self-efficacy beliefs are likely to pre-empt the initiation of coping strategies, accommodations and positive behaviours. Thus, the link between selfefficacy of parents of children with disabilities and a child's abilities and behaviour may be an important factor to consider during the habilitation process.

To date, there is very little research that investigates the association between different aspects of parental cognitive framework, namely, parental self-efficacy and the parent's perception of a specific domain of their child's development, where development is known to be delayed or altered. In this study, the focus is on a particular dimension of disability, namely, communication disability, and the effects of this stressor on maternal levels of self-efficacy within various parental domains. 
The research questions were as follows:

- What are the levels of self-efficacy among a group of mothers of children with disabilities; and

- Is there a correlation between maternal perception of child language abilities and parental levels of self-efficacy?

The aims for this study were therefore to describe self-efficacy ratings of mothers of children with a communication disability and to describe mothers' perception of their child's language ability in order to explore the relationship between perception of child ability (or disability) and maternal sense of competence. This was performed in an attempt to begin to understand the impact that maternal beliefs and perceptions have on parent-child interaction and the habilitation process.

\section{Method}

\section{Research context}

Data collection occurred at four schools catering to children with special needs in the Pretoria area that included pre-school classrooms. Mothers of pre-school children from all the participating schools were asked to participate in the research project. The medium of educational instruction in all the schools is English or Afrikaans. The four schools are located in a predominantly urban middle-class neighbourhoods.

\section{Participants}

Twenty-five mothers participated in the study. Descriptive information that was obtained from this group of mothers included age, employment status and level of education achieved. The mothers' ages at the time of completing the questionnaire ranged from 24 to 48 years, four participants were below 30 years of age, 11 participants were between 30 and 40 years of age, and 10 were between 40 and 50 years of age. Eleven of the participants had completed high school, with 14 having additional diploma or degree training. The majority of the participants were employed in a full-time capacity (16). Of the remaining nine, two worked part-time and seven were currently not employed. The mothers all resided in an area with reasonable proximity to the target schools as their children were day scholars. Of the 25 children whose mothers consented to participate in the study, 19 were male and six were female, and ranged in age from 3 to 6 years; 10 were between 3 and 5 years of age; 
and 15 were between 5 and 6 years of age. The diagnoses of the children were varied and included cerebral palsy, pervasive developmental disorders, language delay and general developmental delay.

\section{Procedure}

The study employed a descriptive survey research design, in which the relationship between maternal rating of parental self-efficacy and mothers' perception of their child's language abilities in mothers of children with a communication disability was investigated using a questionnaire.

The research followed a linear course that involved adapting the questionnaire from existing questionnaires that evaluate the same constructs; translating the questionnaires from English to Afrikaans; conducting a pilot study to test the validity of the survey instrument; and data collection (Harty 2004). The teachers ensured that the questionnaires were sent home with the child and that the mothers acknowledged the receipt of the questionnaires. The mothers were asked to complete the questionnaire in their own time and return it by a given date to the classroom teacher. The researcher's contact telephone number appeared on the permission form, and the researcher telephoned the participants to ensure that they had received the questionnaire and stated that she could be contacted, should they experience any difficulty in completing the questionnaire. After 1 week, the completed questionnaires were collected from the teachers. After coding the data, statistical procedures were implemented and the results were analysed according to the aims and objectives of the study. The procedure was repeated at each of the four schools targeted. A total of 35 questionnaires were distributed to the four schools. The researcher received 21 questionnaires within the initial time frame. The researcher contacted the participants who had not yet returned their questionnaire and requested that they return the questionnaires. At the end of the stipulated time, an additional four questionnaires had been returned. This implies that there is a response rate of $72 \%$. The data from the 25 questionnaires were then coded and analysed.

\section{Instruments}

The measuring instrument used in the main study comprised the self-administered questionnaire consisting of two subsections (a language section and a self-efficacy section) and contained a total of 64 questions. A demographic questionnaire accompanied the questionnaire (Harty 2004). The Self-Efficacy for Parenting Tasks Index (Coleman 1998) was adapted for use as the self-efficacy measure and the 
constructs emotional availability, nurturing, discipline and limit setting, and play were included in the questionnaire for this study. The Receptive-Expressive Emergent Language Test (REEL-2) 2nd edition (Bzoch \& League 1991) formed the basis for the language section of the questionnaire. The questions asked within the REEL-2 were adapted for maternal administration (for more information regarding the adaptations made to the questionnaires, see Harty 2004).

\section{Analysis of data}

The iteman program was used to compute Cronbach alpha values and an item analysis was conducted in order to determine the internal consistency of the questionnaire. Coefficient alpha values for the five self-efficacy subscales are as follows: nurture $=0.82$; discipline $=0.61$; play $=0.74$; teaching $=0.77$; emotional availability $=0.75$. The deletion of items 15 and 23 improved the Cronbach alphas for discipline from 0.56 to 0.61 and teaching from 0.74 to 0.77 . For the language subscale, the alpha coefficients for the receptive and expressive subscales were 0.86 and 0.83 respectively. According to McMillan and Schumacher (2001), an alpha value of 0.70 is acceptable for instruments that measure personality-type traits. According to Brink, 'internal consistency is a useful device for establishing reliability in a highly structured quantitative data-collection method' (Brink 1999, p. 172).

\section{Results and discussion}

\section{Overall ratings of self-efficacy and perception of child language abilities Self-efficacy ratings}

The first sub-aim of this study required a description of the mothers' ratings of their parental self-efficacy. Figure 1 indicates the mean scores of each of the subsections of the self-efficacy questionnaire. The mean self-efficacy subsection scores for the group of participants are relatively high, ranging from $3.3(\mathrm{SD}=0.6)$ to $4.3(\mathrm{SD}=0.5)$. The small variation in standard deviation implies that scores obtained for each section are fairly stable across this group of participants.

In spite of the variations in the mothers' ages as well as in the diagnoses and ages of their children, the mothers in this group are all limited to a specific geographical area. In addition, the majority of the mothers have a diploma or degree, reside in a middleclass neighbourhood and were married at the time of the study. These variables have mediated maternal self-efficacy beliefs in previous studies (Johnston \& Mash 1989; 
Teti \& Gelfand 1991). In addition, these mothers have relatively easy access to services as their child is attending the special school in their area. These factors could have impacted on the mothers' sense of parental self-efficacy and may partially account for the reported mean scores.

Figure 1. Means of the five subsections of the self-efficacy subscale of the questionnaire.

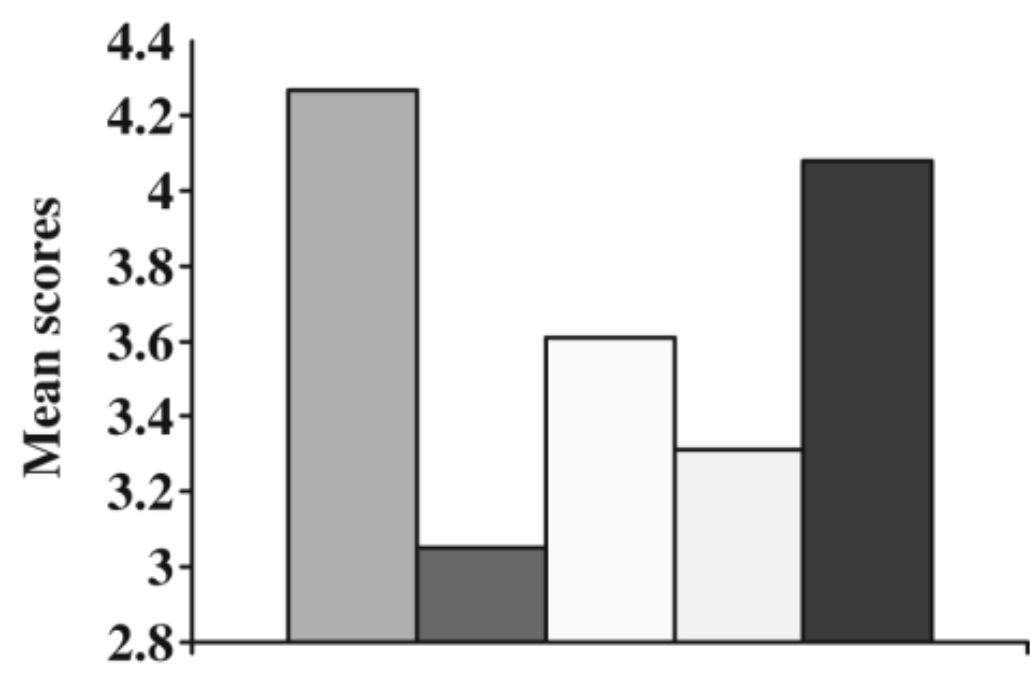

Self-efficacy subsections

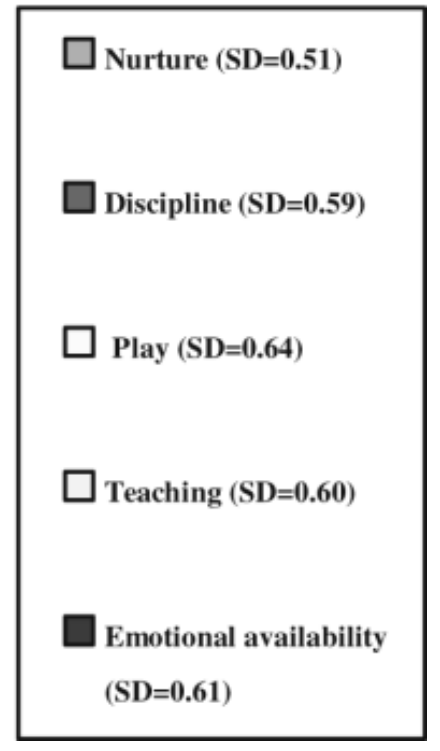

In addition, certain additional constraints of the design and participant selection could have impacted on the high means reported in this study. The relatively small sample size may have contributed to the narrow range in the raw scores and the lower associations and level of correlations reported in Table 2. It could be hypothesized that parents with lower self-efficacy levels may be less likely to return the questionnaires, and as only $72 \%$ of questionnaires were returned, it is possible that the reported results are positively skewed in relation to the target population.

It is clear from Fig. 1 that mothers in this sample have highest self-efficacy on the nurturing and emotional availability subscales. Numerous factors may have impacted on the means obtained for nurturing and emotional availability in this sample. The mothers in this sample are all actively involved in parenting their child as all of the children reside with their parents. This may have enhanced their feelings of competence, as they are currently actively engaged in this role. In other words, these mothers are 'regularly available for the protection, nurturance and care of [their] 
children' (Coleman \& Karraker 1998, p. 47). The fact that all the children have access to services may have impacted positively on the parents' sense of efficacy in the nurturing and emotional availability sections of the self-efficacy questionnaire, as these mothers would feel that they were contributing significantly towards the management of their child's disability and overall well-being. In addition, they all receive support from the school-based intervention teams. The results from this group of mothers indicate that, irrespective of their child's communication difficulties, these mothers feel that they are able to love and provide emotional and physical support to their child.

The lowest self-efficacy rating for these mothers is on the discipline, play and teaching subscales as can be seen in Fig. 1. It would appear as if these participants feel least capable in these parenting domains.

According to Brackett Ballenski and Cook (1982), mothers of typically developing pre-school children (ages 3-5 years) find discipline and limit setting among their most difficult parenting roles. In addition, strong correlations between maternal selfefficacy and child behaviour problems are reported in the literature. A possible explanation could thus be that discipline appears to be a part of parenting, during the pre-school phase, that all mothers (irrespective of whether their child has a disability or not) find challenging. Alternatively, parents of both typically developing children as well as children with disabilities may feel they have low self-efficacy at times where they feel unable to understand their child's behaviour and provide appropriate discipline strategies.

In this group of parents, low ratings on discipline subscale are likely to happen to those parents whose children have lower receptive language abilities, as the strongest correlation between the self-efficacy measure and the language measure occurs between receptive language and discipline subscales, as can be seen in Table 2. This correlation may reinforce the notion that it is child behaviour that affects maternal self-efficacy rather than a child's inherent abilities or impairments.

For the group of mothers in this study, teaching is a challenging part of parenting. This is, however, in direct contrast to results of mothers of typically developing toddlers and pre-schoolers who rated teaching talking, social interaction skills, and numbers and letters among the roles that they felt most comfortable with (Brackett Ballenski \& Cook 1982). The mothers participating in this study all share the 'teaching' role with other professionals whose primary role it is to 'minimize' the 
effects of the disability and promote development. The presence of other professionals (interventionists) may impact on a mother's feelings of efficacy in a variety of ways. First, parental disempowerment within the professional-parent relationship impacts directly on parental competence. Turnbull and colleagues (2000) state that parentprofessional partnerships have been traditionally marked by 'power over' relationships that are characterized by professionals presuming a higher sense of competence and greater knowledge than mothers. This results in professionals exerting the most control in the intervention process. Smith (2003) states that parents of children with disabilities often employ teaching strategies, when in interaction with their child, as they believe that they are the best method of meeting the goals that professionals set in intervention. However, parents often perceive these directive strategies as counterintuitive. von Tetzchner and Grove (2003) state that while in interaction with their child, parents of children using alternative communication forms may find it difficult to utilize strategies that they feel are counter-intuitive. Second, interventionists often alter mothers' orientation towards interacting with a child with a disability. Parents of typically developing children are more likely to structure the environment and provide opportunities for development rather than engage in direct teaching or reinforcement of skills. According to Booth (1997), parents of children without disabilities regard learning as a developmental progress that is formed by a balance between what the child is ready to learn and the environmental supports. Interventionists may pressurize parents into using more directive strategies while in interaction. These strategies may be utilized in an attempt to minimize problematic interaction patterns, as a result of the fact that children with disabilities may be less responsive to environmental and other support. If this is true, then these teaching strategies may negatively impact on interaction, as communication is then used as an educational tool and interferes with good learning opportunities for the child, as Smith (2003) points out.

Parents may therefore employ these direct strategies because these are the strategies that are taught to and expected from them. Although these strategies may help them communicate with their child with a disability (who may be less responsive and therefore more difficult to teach), they are not intuitive and therefore parents feel less competent in utilizing these strategies. This lack of competence may negatively impact on maternal self-efficacy beliefs.

Conclusions from this discussion imply that not only could the lack of competence in this area be a result of the child's inherent characteristics or disability, but it could also 
be a result of professional involvement with the families through intervention, whereby the emphasis of intervention is on teaching and instruction (rather than on facilitating opportunities for development and discovery in a more developmentally congruent fashion). An alternative explanation, however, which may also need to be considered, is that parents with low self-efficacy in certain key parental domains may not have the necessary skills that would allow them to readily participate in the intervention process. In spite of the lack of variability in the self-efficacy scores obtained in this study, it remains evident that self-efficacy is an important aspect to consider during intervention and the habilitation process, as more efficacious parents will participate more actively in the process and may therefore facilitate more favourable outcomes.

\section{Ratings of child language ability}

The second sub-aim of this study requires a description of the mothers' ratings of their child's language ability. The mean for both the receptive and expressive subscales is 3.5 (SD of 0.71 and 0.64 respectively). It is clear that there are no differences in the means obtained for the expressive and receptive language subscales. Although the mean is the most stable measure of central tendency, the median value captures the central point rather than either extreme, 'so that half of the measurements are above the median and half below it' (De Vos 1998, p. 215). The median is therefore used as a measure of central tendency in the further analyses. The median values for individual questions within the expressive and receptive language scales will be discussed below.

\section{Expressive language ability}

The questions on the expressive subscale were divided into expression of various different communication functions. Three of the questions $(16,17$ and 19) pertain to the number of intelligible words spoken by the child, which is not an example of a communication function and is therefore not included in the analysis. The median values of the remaining questions are grouped according to the following communication functions (adapted from Light et al. 1985a):

- requests for objects and actions (questions 18, 22 and 24);

- provision of information (questions 11, 25 and 26);

- expression of self (questions 13, 14 and 23); and

- structured/elicited imitations (questions 12, 15, 20 and 21). 
This information gathered from the analysis indicates that the mothers of these children perceived their child's expressive ability as lowest in the communication functions primarily involved with exchanging and providing information. This is in agreement with Light and colleagues (1985b), who found that children with severe communication disabilities seldom provide unessential information or message clarification.

From the research conducted by Light and colleagues (1985a), it is apparent that children with communication disabilities engage in a greater variety of communicative functions during structured eliciting contexts than in free play interaction. The same tendency can be seen in Table 1 . The high median scores in the structured/elicited imitations category imply that these mothers feel that they often get a response in a structured setting or when they elicit imitations. In addition, Pennington and McConachie (1999) state that children with communication disabilities often forfeited a turn if not obliged to answer. Elicited imitations may be a strategy used by these mothers to force turn-taking in interaction, or as stated previously, imitation is a strategy that parents believe is most likely to achieve the communicative goals set in intervention.

\section{Receptive language abilities}

The questions on the receptive subscales were divided into the following categories: joint attention, functional object use and language comprehension. The median values of the questions are grouped according to the categories just mentioned and are reported in Table 1.

The medians range from 3 (sometimes) to 5 (always) for this subsection of the questionnaire. This is positive in the sense that receptive language abilities form an important building block for the acquisition of an alternative form of communication (Sevcik et al. 1991). From the maternal reports, it is evident that the average child demonstrates the ability to share joint attention and to manipulate objects in a functional way. In terms of symbolic language development, Mundy and Gomes (1997) report that responding and initiating joint attention was significantly correlated with expressive language estimates in typically developing toddlers 14-24 months old. In this study, the maternal reports of high levels of joint attention and language comprehension would therefore not only imply that the children possess the basic 
building blocks that would enable them to successfully use symbolic communication, but that these skills may also positively influence their future language development. The literature indicates that parents are accurate predictors of their child's relative patterns of strength and weaknesses (Dale 1991; Hauerwas \& Addison-Stone 2000). Results from these mothers indicate that they describe similar trends when rating their child's language ability, as professionals have reported (Light et al. 1985a,b; Mirenda \& Donnellan 1986; Conti-Ramsden 1994). These include reporting that children have difficulty providing information, as well as acknowledging that the children respond well to structured contexts where imitation or elicitation is expected. With reference to receptive language, maternal perception of the child's receptive language is, on average, more positive than expressive language, with the mean ranges falling between 3 (sometimes) and 5 (always), and 2 (seldom) and 4 (often) for receptive and expressive language respectively. Therefore, the information obtained from the maternal self-reports appears to corroborate results from studies by Dale (1991), Dinnebeil and Rule (1994), and Hauerwas and Addison-Stone (2000).

To meet the third sub-aim of the present study, correlation statistics were used to measure the correlation existing between maternal self-efficacy ratings and maternal perception of child language abilities and their subscales.

\section{The association between self-efficacy and perception of child language abilities}

As can be seen from Table 2, a positive but weak correlation exists between the overall scores obtained on the efficacy and language subscales of the questionnaire. The Spearman correlation coefficients for the entire efficacy subscale and the expressive $(r=0.2)$ and receptive $(r=0.07)$ subsections of the language subscales, respectively, are also positive but weak. The efficacy subsection appears to have a greater correlation to the mothers' rating of their child's expressive language abilities as opposed to the receptive language abilities, as can be seen in Table 2 .

With regard to the correlations between the individual subsections, the majority of the correlations between the expressive and receptive language subscales and the selfefficacy subscales for this group of participants are positive but weak. None of the correlations are statistically significant. The strongest correlation value found in this study is between maternal perception of receptive language abilities and maternal ratings of self-efficacy $(r=0.38)$.

Coleman and Karraker (1998) suggest that difficulties in behaviour regulation or compliance with routines as well as the presence of behavioural problems may impact 
on parental self-efficacy in the discipline domain. Furthermore, if a child has difficulty providing information and clarification, this may impact on parental selfefficacy as parents may find it difficult to correctly assess situations and provide the correct disciplinary measures (Coleman 1998). An additional explanation would be that it might be more difficult to discipline a child if a parent was unsure whether the child understands the reason for discipline as well as the context within which the disciplining took place.

\section{Conclusions and recommendations for future}

\section{research}

From the literature, it appears as if there is a strong link between perception of child behaviour and parental competence beliefs (Johnston \& Mash 1989; Teti \& Gelfand 1991). However, data from this study do not support these findings.

Table 2 indicates that the correlation between self-efficacy and perceived child language ability is not strong for this group of mothers. Three possible explanations for these findings are explored here. The first is that the link between communication ability and child behaviour is not strong enough to impact on self-efficacy beliefs in this group of parents. The second argument is the fact that the two constructs investigated in the study measure parental skills on very different levels, and therefore strong correlations are unlikely. The third argument brought forward is that the presence of an acknowledged disability as a chronic stressor has unique impact on development and maintenance of parental self-efficacy. The final point of discussion is the impact that self-efficacy may have on the habilitation process, irrespective of the weak correlations presented in this study.

The literature does indicate a close link between behaviour problems and self-efficacy beliefs. However, it is evident from these data that it is not the presence of a communication disability in itself that impacts significantly on self-efficacy levels. What does, however, emerge from this data set is that those parents who are most likely to experience problems disciplining their children (self-efficacy) are those parents whose children have lower receptive language abilities. If one questions why the highest correlation $(0.38)$ present in the data is the correlation between receptive language and discipline, then it is possible to postulate that receptive language ability 
must have some impact on behaviour as the discipline is involved with behaviour management; however, this is not sufficient to manifest in strong correlation values. Furthermore, an analysis of the definitions of self-efficacy and perception brings us closer to understanding why the correlations reported in this study are weak. Sternberg (1995) defines perception as the process whereby we recognize and make sense of what we perceive from the environment. If we refer to the maternal reports of language in this study, we see that the questionnaire required mothers to rate observable skills in their child. Results from this study would appear to confirm the literature that indicates that parents are accurate predictors of their child's relative patterns of strengths and weaknesses (Dale 1991; Hauerwas \& Addison-Stone 2000). However, in spite of maternal accuracy in perceiving child ability, the correlations between self-efficacy and perception of child ability are weak. This implies that although mothers are able to objectively report on child ability, this does not necessarily influence their own competency beliefs.

Self-efficacy is a more subjective self-regulatory process that involves the ability to co-ordinate and orchestrate skills and abilities, in order to attain a particular outcome (Maddux 2002). Perception of the environmental stimuli only sets the stage for selfregulation. Self-regulation implies, in addition to self-observation, the ability to develop courses of action through the prediction of outcomes, and evaluation of behaviours, thoughts and emotions. This is achieved by synthesizing past knowledge and experiences to form beliefs about future event and behaviours. The fact that in this study weak correlations do exist between self-efficacy ratings and ratings of child ability does indeed suggest that accurate perception plays a small part in the process of developing self-efficacy beliefs, but that other factors may also contribute towards this development. In addition, the use of parental report measures may have increased the subjectivity of the data at all levels, thereby limiting the possibility of identifying contributing factors in a more objective manner.

A third reason for the weak correlations may have been the presence of an acknowledged disability. In chronic stress situations, a person's accurate perception of the stressor is not directly indicative of his or her self-efficacy ratings. According to Wheaton (1997), chronic stress is typically open-ended and uses up our resources in coping but does not promise resolution. This is likely to be the case with the presence of a disability - complete resolution of the stressor is unlikely. This implies that in this situation, self-efficacy is not strongly linked to perception of a stressor and the 
ability to avoid or diminish the stress, but is rather linked to the ability to experience positive experiences and outcomes, in spite of the stressor. This would be because parents realize they are unable to change the situation. According to Gottlieb (1997, p. 31), the 'ability to create positive events and experience even transient positive emotions may be particularly important basis for judging efficacy in the context of chronic stress'. In addition, the literature has shown self-efficacy beliefs to be related to the implementation of coping strategies (Donovan 1981; Wells-Parker et al. 1990; Zautra et al. 1997). In other words, for mothers of children with communication difficulties, orientation towards coping with this stress, and coping strategies implemented, could be more indicative of self-efficacy levels than mothers' ability to rate their child's (dis)ability.

Results from Wilder and Granlund (2003) seem to corroborate this assumption within the context of parent-child interaction. They report that no matter how severe the child's communication disability is, mothers believe that they are able to sustain positive interaction with their child. They state that mothers of children with disabilities and mothers of children without disabilities appear to agree on the criteria for healthy interaction and behaviour patterns as well as their role in interaction. Wilder and Granlund (2003, p. 565) conclude that parents 'read the children's signals and lead the interaction according to what the children's capabilities are at that moment'. This implies that successful interaction is not exclusively related to parental perceptions (of their child's competence) in interactions, but rather that maternal perception of their child's behaviour allows the mothers to adjust their interaction strategies so that successful interaction takes place irrespective of the level of the child's ability.

Finally, perhaps the variable of perception of child ability (which was investigated in the current study) does not impact on maternal self-efficacy beliefs as strongly as would constructs that investigate, first, the parent's ability to make positive events happen in spite of the chronic stress and, second, parental ability to cope with the adversity of negative experiences. Scheel and Rieckmann (1998) propose three possible reasons parental self-efficacy may directly impact on the success of child outcomes: (1) it facilitates a proactive approach to parenting; (2) it increases parental willingness to acquire new skills through collaboration with interventionists; and (3) it maximizes the appropriate utilization of support services within the community. Zautra and colleagues (1997) investigated positive event efficacy and coping efficacy 
with a group of carers in a chronic stress context (caring for individuals with dementia). Results from their study indicate that certain appraisals of efficacy are associated with specific ways of coping, i.e. help-seeking and behavioural management was frequently associated with efficacious coping appraisals. In addition, efficacy beliefs shaped the types of coping behaviours that were reported 5 months later. If this is applied to the development and maintenance of parental self-efficacy beliefs, in the presence of a disability, it may imply that determining competence levels based on maternal perception of ability to engage in successful interaction (positive experiences), as well as coping with the differences inherent in interaction (the ability to choose and implement successful accommodations based on the child's behaviour), may provide more definitive information on how disability, parental perception and parental self-efficacy beliefs impact upon each other. In conclusion, although there may not be a direct link between self-efficacy and communication disability, maternal self-efficacy may still however be a valid component to include in habilitation, not as a result of a direct link between perception of child ability and self-efficacy but because the possibility exists of a link between maternal self-efficacy and child outcomes in the sense that more efficacious parents will participate more actively in the process and this will ultimately have a positive impact on the child's development.

\section{References}

- Bandura, A. (1989) Regulation of cognitive processes through perceived selfefficacy. Developmental Psychology, 25, 729-735.

- Bandura, A. (1995) Exercise of personal and collective efficacy in changing societies. In: Self-efficacy in Changing Societies (ed. A. Bandura), pp. 1-45. Cambridge University Press, Cambridge, UK.

- Booth, C. L. (1997) Are parent's beliefs about their children with special needs a framework for individualizing intervention or a focus of change. In: The Effectiveness of Early Intervention (ed. M. J. Guralnick), pp. 625-639. Paul Brookes, Baltimore, MD, USA.

- Brackett Ballenski, C. \& Cook, A. S. (1982) Mothers' perceptions of their competence in managing selected parenting tasks. Family Relations, 31, 489-494. 
- Brink, H. I. (1999) Fundamentals of Research Methodology for Health Care Professionals. Juta, Cape Town, South Africa.

- Bzoch, K. R. \& League, R. (1991) Receptive-Expressive Emergent Language Test (REEL), 2nd edn. Pro-Ed, Austin, MN, USA.

- Coleman, P. K. (1998) Maternal self-efficacy beliefs as predictors of parenting competence and toddlers' emotional, social and cognitive development. Unpublished Dissertation. West Virginia University, Morgantown, WV, USA.

- Coleman, P. K. \& Karraker, K. H. (1998) Self-efficacy and parenting quality: findings and future applications. Developmental Review, 18, 47-85.

- Coleman, P. K. \& Karraker, K. H. (2003) Maternal self-efficacy beliefs, competence in parenting, and toddlers' behaviour and developmental status. Infant Mental Health Journal, 24, 126-148.

- Conti-Ramsden, G. (1994) Language interaction with atypical language learners. In: Input and Interaction in Language Acquisition (eds C. Gallaway \& B. J. Richards), pp. 183-196. Cambridge University Press, New York, NY, USA.

- Dale, P. S. (1991) The validity of a parent report measure of vocabulary and syntax at 24 months. Journal of Speech and Hearing Research, 34, 565-571.

- De Vos, A. S. (1998) Research at Grass Roots: A Primer for the Caring Professions. Van Schaik Publishers, Pretoria, South Africa.

- Dinnebeil, L. A. \& Rule, S. (1994) Congruence between parents' and professionals judgments about the development of young children with disabilities: a review of the literature. Topics in Early Childhood Special Education, 14, 1-25.

- Donovan, B. L. (1981) Maternal learned helplessness and physiologic response to infant crying. Journal of Personality and Social Psychology, 40, 919-926.

- Gottlieb, B. H. (1997) Conceptual and measurement issues in the study of coping with chronic stress. In: Coping with Chronic Stress (ed. B. H. Gottlieb), pp. 3-40. Plenum Press, New York, NY, USA.

- Haidt, J. \& Rodin, J. (1999) Control and efficacy as interdisciplinary bridges. Review of General Psychology, 3, 317-337.

- Harty, M. (2004) The association between maternal self-efficacy and maternal perception of child language competence. Unpublished Dissertation. University of Pretoria, Pretoria, South Africa. 
- Hastings, R. P. \& Brown, T. (2002) Behavior problems of children with autism, parental self-efficacy and mental health. American Journal on Mental Retardation, 107, 222-232.

- Hauerwas, L. B. \& Addison-Stone, C. (2000) Are parents of school-age children with specific language impairment accurate estimators of their child's language skills? Child Language Teaching and Therapy, 16, 73-86.

- Johnston, C. \& Mash, E. J. (1989) A measure of parenting satisfaction and efficacy. Journal of Clinical Child Psychology, 18, 167-175.

- Light, J., Collier, B. \& Parnes, P. (1985a) Communicative interaction between young nonspeaking physically disabled children and their primary caregivers: part I discourse patterns. Augmentative and Alternative Communication, 1, 74-83.

- Light, J., Collier, B. \& Parnes, P. (1985b) Communicative interaction between young nonspeaking physically disable children and their primary caregivers: part II communicative function. Augmentative and Alternative Communication, 1, 98-107.

- McMillan, J. H. \& Schumacher, S. (2001) Research in Education (5th edn). Addison Wesley Longman, New York, NY, USA.

- Maddux, J. E. (2002) Self-efficacy. The power of believing you can. In: Handbook of Positive Psychology (eds C. R. Snyder \& S. J. Lopez), pp. 277-287. Oxford University Press, New York, NY, USA.

- Mash, E. J. \& Johnston, C. (1983) Parental perceptions of child behavior problems, parenting self-esteem and mothers' reported stress in younger and older hyperactive and normal children. Journal of Consulting and Clinical Psychology, 51, 86-99. - Mirenda, P. L. \& Donnellan, A. M. (1986) Effects of adult interaction style on conversational behavior in students with severe communication problems. Language, Speech and Hearing Services in Schools, 17, 126-141.

- Mundy, P. \& Gomes, A. (1997) A skills approach to early language development. Lessons from research on developmental disabilities. In: Communication and Language Acquisition Discoveries from Atypical Development (eds L. B. Adamson \& M. A. Romski), pp. 107-133. Paul Brookes, Baltimore, MD, USA.

- Pennington, L. \& McConachie, H. (1999) Mother-child interaction revisited: communication with non-speaking physically disabled children. International Journal of Language and Communication Disorders, 34, 391-416. 
- Scheel, M. J. \& Rieckmann, T. (1998) An empirically derived description of selfefficacy and empowerment for parents of children identified as psychologically disordered. American Journal of Family Therapy, 26, 15-27.

- Schwarzer, R. (1992) Self-efficacy in the adoption and maintenance of health behaviors: theoretical approaches and a new model. In: Self-Efficacy: Thought Control of Action (ed. R. Schwarzer), pp. 217-243. Hemisphere Publishing Corporation, Washington, DC, USA.

- Sevcik, R. A., Romski, M. A. \& Wilkinson, K. M. (1991) Roles of graphic symbols in the language acquisition process of persons with severe cognitive disabilities. Augmentative and Alternative Communication, 7, 161-170.

- Shelton, S. H. (1990) Developing the construct of general self-efficacy. Psychological Reports, 66, 987-994.

- Smith, M. M. (2003) Environmental influences on aided language development: the role of partner adaptation. In: Augmentative and Alternative Communication Developmental Issues (eds S. von Tetzchner \& N. Grove), pp. 155-175. Whurr Publishers, London, UK.

- Sternberg, R. J. (1995) In Search of the Human Mind. Harcourt Brace College Publishers, New York, NY, USA.

- Teti, D. M. \& Gelfand, D. M. (1991) Behavioural competence among mothers of infants in the first year: the mediational role of maternal self-efficacy. Child Development, 62, 918-929.

- von Tetzchner, S. \& Grove, N. (2003) The development of alternative language form. In: Augmentative and Alternative Communication Developmental Issues (eds S. von Tetzchner \& N. Grove), pp. 1-27. Whurr Publishers, London, UK.

- Turnbull, A. P., Turbiville, V. \& Turnbull, H. R. (2000) Evolution of familyprofessional partnerships: collective empowerment as the model for the early twentyfirst century. In: Handbook of Early Childhood Intervention, 2nd edn (eds J. P. Shonkoff \& S. J. Meisels), pp. 630-650. Cambridge University Press, New York, NY, USA.

- Wells-Parker, E., Miller, D. I. \& Topping, J. S. (1990) Development of control-ofoutcome scales and self-efficacy scales for women in four life roles. Journal of Personality Assessment, 54, 564-575.

-Wheaton, B. (1997) The nature of chronic stress. In: Coping with Chronic Stress (ed. B. H. Gottlieb), pp. 43-73. Plenum Press, New York, NY, USA. 
-Wilder, J. \& Granlund, M. (2003) Behaviour style and interaction between seven children with multiple disabilities and their caregivers. Child: Care, Health and Development, 29, 559-567.

- Zautra, A. J., Hoffman, J. M. \& Reich, J. W. (1997) The role of two kinds of efficacy beliefs in maintaining the well-being of chronically stressed older adults. In: Coping with Chronic Stress (ed. B. H. Gottlieb), pp. 269-290. Plenum Press, New York, NY, USA.

Table 1. Median and range of scores and percentages for the expressive and receptive language subscale

\begin{tabular}{|c|c|c|c|}
\hline Questions & Range & $\begin{array}{l}\text { Median } \\
\text { values }\end{array}$ & Total \\
\hline \multicolumn{4}{|l|}{ Expressive language subscale } \\
\hline \multicolumn{4}{|l|}{ Request for objects and actions } \\
\hline Q18. Request using gestures/pointing & $1-5$ & 4 & $100(n=25)$ \\
\hline $\begin{array}{l}\text { Q22. Combine words in sentences to make } \\
\text { requests }\end{array}$ & $1-5$ & 4 & $100(n=25)$ \\
\hline Q24. Ask and gesture for help & $1-5$ & 4 & $100(n=25)$ \\
\hline \multicolumn{4}{|l|}{ Provision of information } \\
\hline Q 11. Using gestures or words to name things & $1-5$ & 3 & $100(n=25)$ \\
\hline Q 25. Giving the child's gender when asked & $1-5$ & 2 & $100(n=25)$ \\
\hline Q 26. Talks about events in the recent past & $1-5$ & 2 & $100(n=25)$ \\
\hline \multicolumn{4}{|l|}{ Expression of self } \\
\hline Q 13. Uses gestures or to indicate 'No', etc. & $2-5$ & 4 & $100(n=25)$ \\
\hline Q 14. Uses exclamations, i.e. 'o-o' & $1-5$ & 3 & $100(n=25)$ \\
\hline $\begin{array}{l}\text { Q 23. Child refers to himself/herself by name or } \\
\text { approximation }\end{array}$ & $1-5$ & 4 & $100(n=25)$ \\
\hline \multicolumn{4}{|l|}{ Structured/elicited imitations } \\
\hline $\begin{array}{l}\text { Q 12. Child sings or gestures along with familiar } \\
\text { music }\end{array}$ & $1-5$ & 4 & $100(n=25)$ \\
\hline Q 15. Imitation of new words & $2-5$ & 4 & $100(n=25)$ \\
\hline $\begin{array}{l}\text { Q 20. Child repeats words he/she hears in } \\
\text { conversation }\end{array}$ & $1-5$ & 4 & $100(n=25)$ \\
\hline Q 21. Child imitates sounds around him/her & $1-5$ & 4 & $100(n=25)$ \\
\hline
\end{tabular}




\begin{tabular}{|c|c|c|c|}
\hline Questions & Range & $\begin{array}{l}\text { Median } \\
\text { values }\end{array}$ & Total \\
\hline \multicolumn{4}{|l|}{ Receptive language subscale } \\
\hline \multicolumn{4}{|l|}{ Joint attention } \\
\hline $\begin{array}{l}\text { Q 1. Interested when looking at pictures with } \\
\text { mother }\end{array}$ & $1-5$ & 3 & $100(n=25)$ \\
\hline $\begin{array}{l}\text { Q 2. Recognizes objects/pictures when named by } \\
\text { mother }\end{array}$ & $1-5$ & 4 & $100(n=25)$ \\
\hline $\begin{array}{l}\text { Q 3. Identifies objects in room when mother } \\
\text { requests so }\end{array}$ & $2-5$ & 4 & $100(n=25)$ \\
\hline \multicolumn{4}{|l|}{ Functional use of objects } \\
\hline Q 5. Recognizes common objects when shown & $1-5$ & 3 & $100(n=25)$ \\
\hline Q 8. Recall names of items when given their uses & $1-5$ & 4 & $100(n=25)$ \\
\hline \multicolumn{4}{|l|}{ Language comprehension } \\
\hline Q 4. Understands words such as her, me and you & $1-5$ & 3 & $100(n=25)$ \\
\hline Q 6. Responds to the meaning of what people say & $1-5$ & 4 & $100(n=25)$ \\
\hline Q 7. Recognizes family names, i.e. baby, brother & $3-5$ & 5 & $100(n=25)$ \\
\hline $\begin{array}{l}\text { Q 9. Understands words that describe things, i.e. } \\
\text { pretty }\end{array}$ & $1-5$ & 3 & $100(n=25)$ \\
\hline $\begin{array}{l}\text { Q 10. Understands words that tell where things } \\
\text { are }\end{array}$ & $1-5$ & 4 & $100(n=25)$ \\
\hline
\end{tabular}

Table 2. Spearman correlation coefficients for the self-efficacy subscales of the adapted measure

\begin{tabular}{|l|l|l|l|l|l|l|}
\hline & \multicolumn{5}{|c|}{ Parenting self-efficacy subscales } \\
\cline { 2 - 5 } & Nurture & Discipline & Play & Teaching & Emotional availability \\
\hline Language subscales & 0.06 & 0.38 & 0.18 & 0.01 & -0.06 \\
\hline Receptive & 0.06 & -0.10 & 0.17 & 0.05 & 0.20 \\
\hline Expressive & 0.22 & &
\end{tabular}

